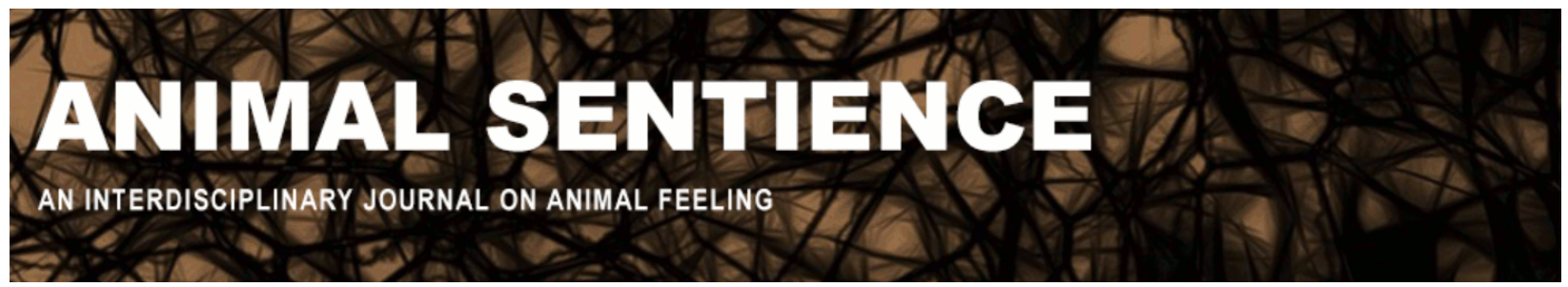

Ross, Don (2018) Two fallacies in comparisons between humans and nonhumans. Animal Sentience 23(13)

DOI: $10.51291 / 2377-7478.1388$

Date of submission: 2019-01-29

Date of acceptance: 2019-02-11 (c) 


\title{
Two fallacies in comparisons between humans and non-humans
}

\author{
Commentary on Chapman \& Huffman on Human Difference
}

\author{
Don Ross \\ University College Cork, Ireland
}

\begin{abstract}
The hypothesis that humans are superior to non-humans by virtue of higher cognitive powers is often supported by two recurrent fallacies: (1) that any competence shown by humans but not by our closest living relatives (apes) must be unique to humans; and (2) that grades of intelligence can be inferred from behavior without regard to motivational structures.
\end{abstract}

Don Ross is Professor and Head, School of Sociology, Philosophy, Criminology, Government, and Politics at University College Cork, Ireland; Professor, School of Economics, University of Cape Town, South Africa; and Program Director for Methodology, Center for Economic Analysis of Risk, Georgia State University, Atlanta. An experimental economist specializing in risk and time preferences and their biological origins, including in nonhumans, he is also a philosopher of science. Website

There is no room for doubt that most human cultural traditions have (1) taken humans to be superior to non-human animals in moral worth, that this has (2) rationalized disregard for nonhuman welfare and indeed extreme cruelty, and (3) been buttressed by assumptions of human intellectual superiority. Here I will point to two fallacies in reasoning that continue to sustain belief in human cognitive supremacy even among many scientifically literate people in the $21^{\text {st }}$ century.

The first is the assumption that the tree of life resembles a tree not just in having branches, but in having a bottom and a top, where greater heights are associated with higher intelligence. On this picture, our closest living relatives, the apes, are assumed to be immediately below us in the ontogenetic cognitive hierarchy. This licenses an assumption that whatever we celebrate in ourselves as a cognitive endowment - for example, language characterized by large lexicons, reference to absent or hypothetical objects and events, and recursive syntax - if apes cannot seem to replicate it to our level, then no other animal can (Berwick and Chomsky 2015). Thus we conclude that we are unique bearers of the endowment in question.

Beginning from the assumption that humans are uniquely clever apes, we find the reasoning extended to supposing that apes are uniquely clever mammals, that mammals are uniquely clever vertebrates, and so on.

This ignores convergent evolution, which is ubiquitous in nature (McGhee 2011). The nearest living relatives of birds are lizards, who cannot fly. It obviously does not follow that flight is restricted to birds. Similarly, while it is true that even apes that have been painstakingly taught sign language or keyboard-based language have not displayed the facility with it that is 
common among humans past early childhood, it does not follow that no other animals have language. It is now recognized by linguists that various other animals communicate about states of affairs that are outside their current perceptual fields (Bickerton 2014). A smaller set of nonhumans - at least toothed whales, elephants, parrots and corvids - have enough variation in their signaling repertoires to encode both large lexicons and syntax (Ford 1991; Langbauer 2000; Pepperberg 2002; Saulitis et al. 2005; Soltis et al. 2005a, 2005b; Strager 1995). These same animals display complex enough social coordination that language would not be an implausibly expensive capacity for natural selection to have sustained in them. Prior to studying the patterns in their communications using deep learning algorithms, we have no direct evidence for language in these non-humans. But there is also no evidence against it.

A second fallacy is to assume that whatever we consider a sign of cognitive achievement in humans that non-humans don't generally do is something that they lack the capacity to do. This ignores the question of motivation. I noted above that even apes who have learned some human language do not use it as adolescent and adult humans do, to state and defend opinions and to tell stories about spatially or temporally distant or imaginary events (Anderson 2004; Penn et al. 2008). This is often assumed without further ado to reveal a limitation in their 'intelligence'. This is partly circular; as Chapman \& Huffman point out, we tend to define 'intelligence' as denoting whatever we think most distinguishes the minds of humans. Consider that humans do not make and keep memory records of the scent traces of all their local conspecifics, despite our having the technological instruments to do so if we saw a point to it. Dogs might consequently regard us as revealing our stupidity, if they reasoned about humans as we typically reason about non-humans. Chimps and bonobos might not use language to construct ideologies and fictions - or for anything more than to express desires, as languagetaught apes do do - because their motivational structure attaches no value to such activity. Story-telling is not intrinsically valuable; it is valuable to us. (And, again, we do not know that it isn't also valuable to orcas or elephants, and practiced by them.)

The metaphor of the great chain of being dies hard. But it is not scientific, and the cruelty and violence it encourages are heartbreaking.

\section{References}

Anderson, S. (2004). Doctor Doolittle's Delusion. Yale University Press.

Berwick, R., \& Chomsky, N. (2015). Why Only Us: Language and Evolution. MIT Press.

Bickerton, D. (2014). More Than Nature Needs. Harvard University Press.

Chapman, C. A. and Huffman, M. A. (2018) Why do we want to think humans are different?

Animal Sentience 23(1)

Ford, J. (1991). Vocal traditions among resident killer whales (Orcinus orca) in coastal waters of

British Columbia. Canadian Journal of Zoology 69: 1454-1483.

Langbauer, W. (2000). Elephant communication. Zoo Biology 19: 425-445.

McGhee, G. (2011). Convergent Evolution: Limited Forms Most Beautiful. MIT Press.

Penn, D., Holyoak, K., \& Povinelli, D. (2008). Darwin's mistake: Explaining the discontinuity

between human and nonhuman minds. Behavioral and Brain Sciences 31: 109-178. 
Pepperberg, I. (2002). The Alex Studies: Cognitive and Communicative Abilities of Grey Parrots. Harvard.

Saulitis, E., Matkin, C., \& Fay, F. (2005). Vocal repertoire and acoustic behavior of the isolated AT1 killer whale subpopulation in southern Alaska. Canadian Journal of Zoology 83: 10151029.

Soltis, J., Leong, K., \& Savage, A. (2005a). African elephant vocal communication I: antiphonal calling behaviour among affiliated females. Animal Behaviour 70: 579-587.

Soltis, J., Leong, K., \& Savage, A. (2005b). African elephant vocal communication II: rumble variation reflects the individual identity and emotional state of callers. Animal Behaviour 70 : 589-599.

Strager, H. (1995). Pod-specific call repertoires and compound calls of killer whales, Orcinus orca Linnaeus, 1758, in the waters of northern Norway. Canadian Journal of Zoology 73 : 1037-1047. 